\title{
Indomethacin induces apoptosis via a MRPI-dependent mechanism in doxorubicin-resistant small-cell lung cancer cells overexpressing MRPI
}

\author{
DJA de Groot', M van der Deen', TKP Le', A Regeling', S de Jong' and EGE de Vries*,I \\ 'Department of Medical Oncology, University of Groningen and University Medical Center, PO Box 30.00I, 9700 RB, Groningen, The Netherlands
}

\begin{abstract}
Small-cell lung cancers (SCLCS) initially respond to chemotherapy, but are often resistant at recurrence. The non-steroidal anti-inflammatory drug indomethacin is an inhibitor of multidrug resistance protein I (MRPI) function. The doxorubicin-resistant MRPI-overexpressing human SCLC cell line $\mathrm{GLC}_{4}$-Adr was highly sensitive for indomethacin compared with the parental doxorubicin-sensitive line $\mathrm{GLC}_{4}$. The purpose of this study was to analyse the relationship between hypersensitivity to indomethacin and MRPI overexpression. The experimental design involved analysis of the effect of MRPI downregulation on indomethacininduced cell survival and apoptosis in $\mathrm{GLC}_{4}-\mathrm{Adr}$ and $\mathrm{GLC}_{4}$, using siRNA. In addition the effect of indomethacin on glutathione levels and mitochondrial membrane potential was investigated. Small interfering RNAs directed against MRPI reduced MRPI mRNA levels twofold and reduced efflux pump function of MRPI, which was reflected by a I.8-fold higher accumulation of MRPI substrate carboxyfluorescein, in si-MRPI versus si-Luciferase-transfected $\mathrm{GLC}_{4}$-Adr cells. Multidrug resistance protein I downregulation decreased initial high apoptosis levels 2-fold in $\mathrm{GLC}_{4}$-Adr after indomethacin treatment for $24 \mathrm{~h}$, and increased cell survival (IC50) from $22.8 \pm 2.6$ to $30.4 \pm 5$. I $\mu \mathrm{M}$ following continuous indomethacin exposure. Multidrug resistance protein I downregulation had no effect on apoptosis in $\mathrm{GLC}_{4}$ or on glutathione levels in both lines. Although indomethacin $(20 \mu \mathrm{M})$ for $2 \mathrm{~h}$ decreased glutathione levels by $31.5 \%$ in $\mathrm{GLC}_{4}-\mathrm{Adr}$, complete depletion of cellular glutathione by L-buthionine $(\mathrm{S}, \mathrm{R})$-sulphoximine only resulted in a small increase in indomethacin-induced apoptosis in $\mathrm{GLC}_{4}-\mathrm{Adr}$, demonstrating that a reduced cellular glutathione level is not the primary cause of indomethacin-induced apoptosis. Indomethacin exposure decreased mitochondrial membrane potential in GLC 4 -Adr cells, suggesting activation of the mitochondrial apoptosis pathway. Indomethacin induces apoptosis in a doxorubicin-resistant SCLC cell line through an MRPI-dependent mechanism. This may have implications for the treatment of patients with MRPI-overexpressing tumours. British Journal of Cancer (2007) 97, 1077- 1083. doi:I0.1038/sj.bjc.66040I0 www.bjcancer.com
\end{abstract}

Published online 16 October 2007

(c) 2007 Cancer Research UK

Keywords: indomethacin; apoptosis; MRPI; doxorubicin resistance; SCLC

Lung cancer is the tumour type with the highest incidence in males in the Western world, and its incidence in females is rising. Smallcell lung cancer (SCLC) represents about $25 \%$ of all lung cancers. Small-cell lung cancers are well known for their initial sensitivity to chemotherapeutic agents. However, they frequently recur, and it is at this time that the tumours become drug resistant (Glisson, 2003). Common mechanisms of drug resistance are the overexpression of drug transporters and the resistance to apoptosis induction in tumour cells. The ATP-binding cassette (ABC) family of transport proteins is the major family of drug transporters. The multidrug resistance protein 1 (MRP1), a member of the ABC family of drug transporters, can act as an efflux pump for a number of chemically unrelated agents. Intracellular glutathione (GSH) can be conjugated to these agents by glutathione-

\footnotetext{
*Correspondence: Dr EGE de Vries;

E-mail: e.g.e.de.vries@int.umcg.nl

Revised 16 August 2007; accepted 30 August 2007; published online 16 October 2007
}

$S$-transferase. Multidrug resistance protein 1 transports GSH, GSH conjugates and unconjugated cytotoxic drugs to the extracellular compartment (Cole et al, 1994; Müller et al, 1994; Zaman et al, 1994; Paul et al, 1996; Ballatori et al, 2005). Glutathione is required for several other cellular functions such as protein and DNA synthesis, cell cycle regulation, protection against oxidative damage and detoxification of toxins (Wang and Ballatori, 1998).

The non-steroidal anti-inflammatory drug indomethacin is a well-known inhibitor of MRP1 function. It inhibits glutathione-Stransferase and also functions as a direct substrate for MRP1 (Draper et al, 1997; Touhey et al, 2002). In addition, in low concentrations indomethacin can increase GSH efflux (Evers et al, 2000). We previously reported that exposure of the MRP1overexpressing doxorubicin-resistant SCLC cell line $\mathrm{GLC}_{4}$-Adr to indomethacin resulted in caspase-8- and caspase-9-dependent apoptosis induction, suggesting the involvement of the extrinsic and intrinsic apoptosis pathways. In contrast, exposure of the parental cell line $\mathrm{GLC}_{4}$ to indomethacin did not induce apoptosis (De Groot et al, 2005). Indomethacin as well as MK571 increase doxorubicin sensitivity in these $\mathrm{GLC}_{4}$ cell lines. The use of this 
isogenic model implies that factors rendering $\mathrm{GLC}_{4}-\mathrm{Adr}$ resistant to doxorubicin are very likely also be responsible for indomethacin sensitivity. Studies investigating the increase in drug sensitivity after indomethacin exposure in human and murine cell lines showed that the drug-sensitizing effect of indomethacin was not prostaglandin dependent, but was dependent on glutathione-S-transferase, or caused by direct inhibition of glutathione-S-transferase (Draper et al, 1997). Insight into this mechanism might result in a simple, relatively non-toxic way to exploit MRP1 overexpression for apoptosis induction in chemotherapy-resistant cells. In this study, we therefore investigated whether indomethacin-induced apoptosis is related to MRP1 overexpression. In addition the mechanism of indomethacininduced apoptosis with respect to MRP1 function and GSH levels was studied.

\section{MATERIALS AND METHODS}

\section{Cell lines}

The $\mathrm{GLC}_{4}$ cell line was derived from a pleural effusion in our laboratory and kept in culture in RPMI 1640 medium supplemented with $10 \%$ heat-inactivated foetal calf serum (FCS) (both from Life Technologies, Breda, The Netherlands). The $\mathrm{GLC}_{4}$-Adr subline acquired resistance not only to doxorubicin but also to a wide range of other chemotherapeutic agents, by stepwise increases in doxorubicin concentrations in the culture medium (Zijlstra et al, 1987; De Jong et al, 1990; Meijer et al, 1991; Müller et al, 1994). $\mathrm{GLC}_{4}$-Adr is $190.6 \pm 16.2$-fold more resistant to doxorubicin than $\mathrm{GLC}_{4}$. The doxorubicin resistance in $\mathrm{GLC}_{4}-\mathrm{Adr}$ is due to a downregulation of the activity of DNA-topoisomerase II (TOPO II) and amplification and consequent 79-fold overexpression of the $M R P 1$ gene. $\mathrm{GLC}_{4}$-Adr was maintained in culture medium $1.2 \mu \mathrm{M}$ doxorubicin twice weekly. $\mathrm{GLC}_{4}-\mathrm{Adr}$ was cultured without doxorubicin for 20 days before experiments. Cells were cultured at $37^{\circ} \mathrm{C}$ in a humidified atmosphere with $5 \% \mathrm{CO}_{2}$. Cells from exponentially growing cultures were used for all experiments. Forty-eight hours of indomethacin $(50 \mu \mathrm{M})$ treatment induces $50.6 \pm 14.6 \%$ apoptosis in $\mathrm{GLC}_{4}$ - $\mathrm{Adr}$ and $2.1 \pm 1.5 \%$ apoptosis in $\mathrm{GLC}_{4}$.

\section{Chemicals, media and reagents}

HAM/F12 and DMEM medium (minimal essential medium (MEM, supplemented with Earle's salts and L-glutamine), oligofectamine, RPMI 1640, phosphate-buffered saline (PBS), Hoechst 33258, MitoTracker Red $\mathrm{CM}-\mathrm{H}_{2}$ XRos and Trizol were purchased from Invitrogen Life Technologies (Breda, The Netherlands)). Carboxyfluorescein diacetate (CFDA), 3-[4,5-dimethylthiazol-2-yl]-2,5-diphenyltetrazolium bromide (MTT), L-buthionine (S,R)-sulphoximine (BSO), glutathione reductase, nicotinamide adenine dinucleotide phosphate (NADPH), trichloric acid (TCA), GSH, 5,5'-dithiobis(2-nitrobenzoic acid) (DTNB) and propidium iodide (PI) were obtained from Sigma-Aldrich BV (Zwijndrecht, The Netherlands); DNase-I was from Roche Diagnostics (Mannheim, Germany), doxorubicin-HCl from Pharmachemie BV (Haarlem, The Netherlands), ethylenedinitrilo tetraacetic acid disodiumsalt dihydrate (EDTA) from Merck (Darmstadt, Germany). MK571 was purchased from Omnilabo (Breda, The Netherlands), the qPCR core kit from Eurogentec (Seraing, Belgium), the RNeasy kit from Qiagen (Venlo, The Netherlands) and Vitrogen from Nutacon (Leimuiden, The Netherlands).

\section{Flow cytometric detection of MRP1 activity}

To determine MRP1 activity, cells were incubated with $0.1 \mu \mathrm{M}$ carboxyfluorescein diacetate as described previously (Van der Kolk et al, 1998), with slight modifications. Carboxyfluorescein diacetate is converted intracellularly to carboxyfluorescein (CF), which is a fluorescent MRP1 substrate. To establish the effect of indomethacin on the activity of MRP $1,1 \times 10^{6}$ cells were incubated in $0.5 \mathrm{ml}$ RPMI 1640 medium $\left(37^{\circ} \mathrm{C}, 5 \% \mathrm{CO}_{2}, 1 \mathrm{~h}\right)$ with CFDA. MK571 $(50 \mu \mathrm{M})$ served as a positive control for the inhibition of MRP1 activity. Cells were pelleted for $15 \mathrm{~s}$ at $12000 \mathrm{~g}$ and resuspended in $350 \mu \mathrm{l}$ ice-cold RPMI medium with $0.1 \mu \mathrm{g} \mathrm{ml}^{-1}$ PI to distinguish dead cells from living cells. Fluorescence of CF was analysed with a FACS Caliber flow cytometer (BD Biosciences, San Jose, CA, USA). A total of 10000 events were measured per sample. The Winlist 5.1 programme (Verity Software House Inc., Topsham, ME, USA) was used to calculate mean fluorescence intensity (MFI) values. The efflux-blocking factor (BF) was defined as the ratio between MFI of substrate plus modulator and MFI of substrate. All measurements were corrected for the negative control (without indomethacin). Experiments were performed in triplicate.

\section{RNA interference}

To explore the role of MRP1 in indomethacin-induced apoptosis, siRNAs directed against MRP1 (si-MRP1) and luciferase (si-Luciferase, negative control) were purchased from Eurogentec (Maastricht, The Netherlands). The sense sequence for si-MRP1 was $5^{\prime}$-GGAGUGGAACCCCUCUCUG- $3^{\prime}$ and the antisense sequence was $5^{\prime}$-CAGAGAGGGGUUCCACUCC- $3^{\prime}$. For si-Luciferase, the sense sequence was $5^{\prime}$-CUUACGCUGAGUACUUCGA- $3^{\prime}$ and the antisense sequence was $5^{\prime}$-UCGAAGUACUCAGCGUAAG- $3^{\prime}$.

$\mathrm{GLC}_{4}$ and $\mathrm{GLC}_{4}$-Adr cells were seeded in six-wells plates at a concentration of $3 \times 10^{5}$ well $^{-1}$. The next day, transfection was performed using $200 \mathrm{~nm}$ oligonucleotides with Oligofectamine and RPMI 1640, in the absence of FCS according to the manufacturer's instructions. After $4 \mathrm{~h}$ the medium containing FCS was added to an FCS solution of final concentration of $10 \%$. Multidrug resistance protein 1 function assays with flow cytometre and RNA extraction were carried out $48 \mathrm{~h}$ after siRNA transfection.

\section{RNA isolation and quantitative RT - PCR}

Cells treated with siRNA for $48 \mathrm{~h}$ were washed with ice-cold PBS and resuspended in $1 \mathrm{ml}$ of Trizol. After $5 \mathrm{~min}$ incubation at room temperature, the lysate was stored at $-80^{\circ} \mathrm{C}$ until use. RNA was isolated according to standard manufacturer's protocols, followed by a DNase-I treatment. For RNA purification, the RNeasy kit was used following standard procedures. RNA ( $800 \mathrm{ng}$ ) was subjected to a complementary DNA (cDNA) synthesis reaction.

Quantitative reverse transcriptase-polymerase chain reaction (RT-PCR) was performed using the ABI PRISM 7700 sequence detector (Applied Biosystems, Foster City, USA, USA) as described previously (Ros et al, 2003). In brief, a qPCR core kit was used and the PCR mixture contained $900 \mathrm{~nm}$ of sense and antisense primers, $200 \mathrm{nM}$ of fluorogenic probe (labelled by a $5^{\prime}$ FAM reporter and a $3^{\prime}$ TAMRA quencher). Each sample was analysed in duplicate. Primer sequences for MRP1 were as follows: for the sense strand, $5^{\prime}$-GGTG GGCCGAGTGGAATT-3'; for the antisense strand, 5'-TTGATGTGC CTGAGAACGAAGT $-3^{\prime}$ and for the probe strand, $5^{\prime}$ FAM-CTGCCT GCGCTACCGAGAGGACCT-TAMRA3'. Primer sequences for the housekeeping gene GAPDH were for the sense strand $5^{\prime}$-GGTGGT CTCCTCTGACTTCAACA- ${ }^{\prime}$, for the anti-sense strand $5^{\prime}$-GTGGTC GTTGAGGGCAATG- $3^{\prime}$ and for the probe strand $5^{\prime}$ FAM-ACACCC ACTCCTCCACCTTTGACGC-TAMRA3'. Cycle numbers at which the sample fluorescence signal increases above a fixed threshold level $\left(C_{\mathrm{t}}\right.$ value $)$ correlate inversely with mRNA levels.

\section{MTT assay}

The cell lines were cultured in HAM/F12 and DMEM medium (1:1) supplemented with $20 \%$ FCS. The effect of doxorubicin and 
indomethacin on survival was tested in an MTT assay as described previously (Timmer-Bosscha et al, 1989). Cells were incubated with a range of indomethacin concentrations for 4 days at $37^{\circ} \mathrm{C}$ and $5 \% \mathrm{CO}_{2}$ in a humidified environment. The effect of si-MRP1 downregulation on cell survival was tested in the MTT assay using continuous incubation with indomethacin. After a 4-day culture period, MTT ( $5 \mathrm{mg} \mathrm{ml}^{-1}$ in PBS) was added and formazan crystal production was measured as described previously. Controls consisted of media without cells (background extinction) and cells incubated with medium instead of the cytotoxic agent. Experiments were performed three times in quadruplicate.

\section{Apoptosis assay}

The effect of GSH on indomethacin-mediated apoptosis induction was tested in cells $\left(1.5 \times 10^{4}\right.$ well $\left.^{-1}\right)$ cultured in 96-wells plates and preincubated with $250 \mu \mathrm{m}$ BSO for $24 \mathrm{~h}$. Apoptosis was induced by adding different concentrations of indomethacin for $24 \mathrm{~h}$.

In addition, $\mathrm{GLC}_{4}-\mathrm{Adr}$ cells were transfected with si-MRP1 and si-Luciferase. After $48 \mathrm{~h}$ these cells were plated in 96-wells plates and exposed to different concentrations of indomethacin for $24 \mathrm{~h}$. Acridine orange staining $\left(10 \mu \mathrm{g} \mathrm{m}^{-1}\right)$ was used to identify apoptotic cells. Apoptosis was defined as the appearance of apoptotic bodies and/or chromatin condensation, viewed using a fluorescence microscope. Results were expressed as the percentage of apoptotic cells in a culture by counting at least 200 cells per well. All apoptosis assays were performed in duplicate and repeated three times.

\section{Glutathione assay}

Free GSH was measured by a modified method as described by Allen et al (2000). Cells were plated in $25-\mathrm{cm}^{2}$ flasks and exposed to $250 \mu \mathrm{m}$ BSO for $24 \mathrm{~h}$ to achieve adequate GSH depletion. Cells were exposed to indomethacin and $50 \mu \mathrm{M}$ MK571 for $2 \mathrm{~h}$ to evaluate short-term effect of these drugs on GSH levels. Cells were isolated from six-well plates and washed in PBS. Protein was precipitated with 5\% TCA and the precipitate was spun down at $4500 \mathrm{~g}$. The supernatant was diluted to $1 \mathrm{mg} \mathrm{ml}^{-1}$ protein. A $150-\mu \mathrm{l}$ volume of the supernatant was put in a 96-well plate in different dilutions. Ellman's reagents ( $12 \mathrm{~mm}$ DTNB, $5 \mathrm{~mm}$ EDTA in $125 \mathrm{~mm}$ phosphate buffer) and $10 \mu \mathrm{l}$ of $125 \mathrm{~mm}$ phosphate buffer containing $5 \mathrm{~mm}$ EDTA and $0.4 \mathrm{U}$ of glutathione reductase were added to the samples. The reaction was started by the addition of $20 \mu \mathrm{l} 5.6 \mathrm{mM}$ NADPH in $125 \mathrm{~mm}$ phosphate buffer containing 5 mM EDTA. 5,5'Dithio-bis(2-nitrobenzoic acid reduction produced in the assay was measured at $405 \mathrm{~nm}$. All GSH assays were performed three times.

\section{Mitochondrial membrane potential}

To determine whether there is an absolute decrease in fluorescence, $3 \times 10^{5}$ cells were seeded in six-well plates and exposed to different concentrations of indomethacin for $24 \mathrm{~h}$. MitoTracker $\operatorname{red}^{\mathbb{R}}(300 \mathrm{nM})$ was added for $45 \mathrm{~min}$ at $37^{\circ} \mathrm{C}$ and cells were analysed with an Elite flow cytometer (Bechman Coulter, Fullerton, CA, USA). MitoTracker red fluorescence was measured in the PE channel. Experiments were performed three times and a representative example was shown.

\section{Statistical analysis}

Paired Student's $t$-test, independent samples $t$-test or one-sample $t$-test was used to calculate statistical differences. Differences were considered significant when $P<0.05$.

\section{RESULTS}

The effect of MRP1 downregulation on indomethacin-induced apoptosis and cell death

Compared with the parental cell line $\mathrm{GLC}_{4}$, the doxorubicinresistant sub-line $\mathrm{GLC}_{4}$-Adr strongly overexpresses MRP1 and is highly sensitive to indomethacin (De Groot et al, 2005). The role of MRP1 in indomethacin sensitivity was investigated using an MRP1 siRNA approach. Efficient downregulation of MRP1 mRNA was demonstrated, since the relative MRP1 mRNA expression levels, as determined with quantitative $\mathrm{RT}-\mathrm{PCR}$, were reduced to $55.2 \pm 18.3 \%$ in si-MRP1-transfected $\mathrm{GLC}_{4}-\mathrm{Adr}$ cells, and to $44.9 \pm 1.1 \%$ in si-MRP1-transfected $\mathrm{GLC}_{4}$ compared with their respective si-Luciferase-transfected controls. The absolute MRP1 mRNA expression levels, however, were 79 times higher in $\mathrm{GLC}_{4}$-Adr compared with $\mathrm{GLC}_{4}$ cells.

The $\mathrm{CF}$ accumulation following $1 \mathrm{~h}$ CFDA exposure was used to determine the MRP1 function in siRNA-transfected $\mathrm{GLC}_{4}-\mathrm{Adr}$ cells. Carboxyfluorescein accumulation was $84 \pm 19 \%$ higher in the si-MRP1-transfected cells compared with the si-Luciferasetransfected cells, indicating that the MRP1 function in $\mathrm{GLC}_{4}-\mathrm{Adr}$ was indeed decreased as a result of MRP1 mRNA downregulation (Figure 1).

Indomethacin-induced apoptosis was clearly reduced in siMRP1-transfected $\mathrm{GLC}_{4}$-Adr cells (Figure 2). For example, a reduction in apoptosis (2.0 \pm 0.05 -fold) was observed at $75 \mu \mathrm{M}$ indomethacin. At higher indomethacin concentrations, similar reductions were observed in si-MRP1-transfected $\mathrm{GLC}_{4}$-Adr cells compared with si-Luciferase-transfected $\mathrm{GLC}_{4}$-Adr cells. However, indomethacin concentrations up to $150 \mu \mathrm{M}$ did not induce apoptosis in either si-MRP1- or si-Luciferase-transfected $\mathrm{GLC}_{4}$ cells (data not shown).

Apart from a reduction in apoptosis, an increased survival following indomethacin exposure was also observed in si-MRP1transfected $\mathrm{GLC}_{4}$-Adr cells (Figure 3). The $\mathrm{IC}_{50}$ for indomethacin was $22.8 \pm 2.6 \mu \mathrm{M}$ in si-Luciferase-transfected $\mathrm{GLC}_{4}-\mathrm{Adr}$ and $30.4 \pm 5.1 \mu \mathrm{M}$ in si-MRP1-transfected $\mathrm{GLC}_{4}$-Adr $(P<0.05)$. No differential effect on cell survival was observed between $\mathrm{GLC}_{4}$

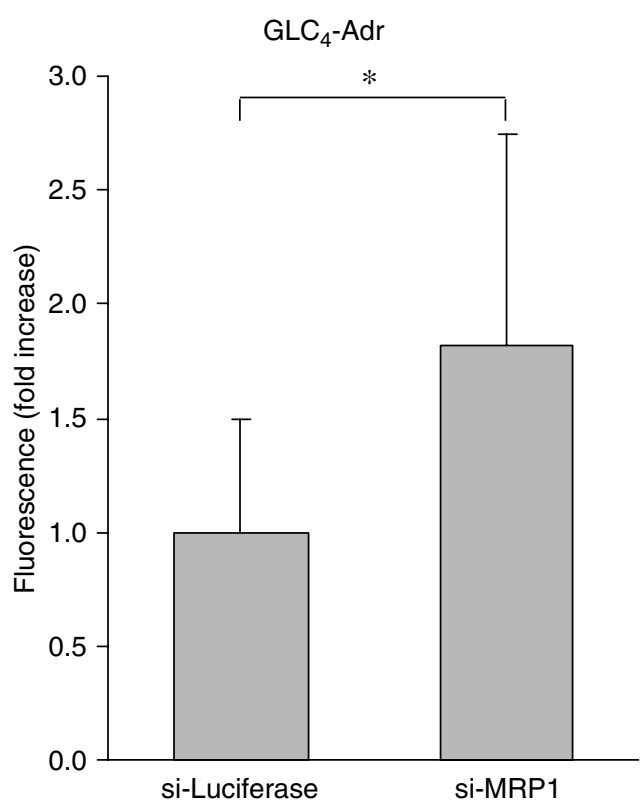

Figure I Relative cellular CF fluorescence after si-MRPI and siLuciferase treatment $(* P<0.05)$ 


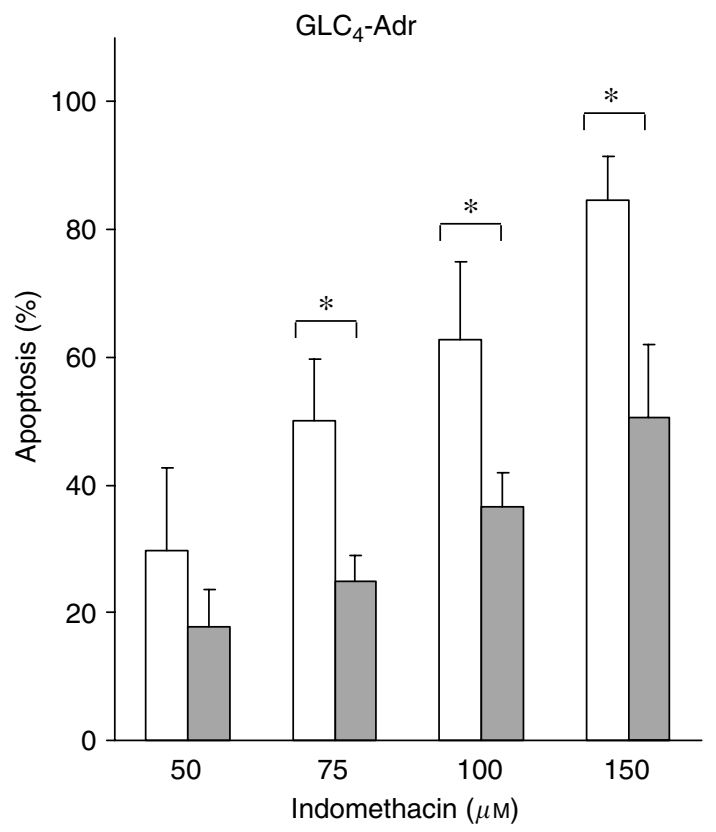

Figure 2 Indomethacin-induced apoptosis in $\mathrm{GLC}_{4}-\mathrm{Adr} 48 \mathrm{~h}$ after siLuciferase transfection (white) or si-MRPI transfection (grey). Cells were exposed to indomethacin for $24 \mathrm{~h}$. No apoptosis was observed in GLC (data not shown). Data represent the mean \pm s.d. of three independent experiments $(* P<0.05)$.
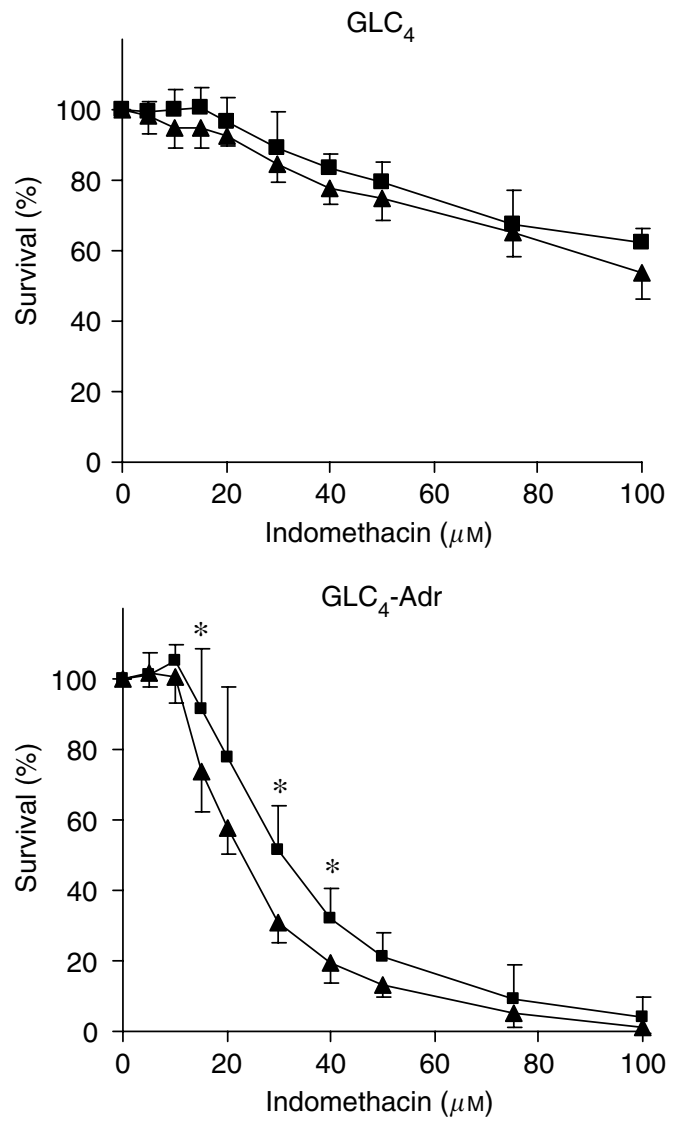

Figure 3 Indomethacin-induced growth inhibition. Survival of $\mathrm{GLC}_{4}$ and $\mathrm{GLC}_{4}-\mathrm{Adr}$ cells $48 \mathrm{~h}$ after si-Luciferase (triangle) or si-MRPI (square) transfection was compared. Data represent the mean \pm s.d. of three independent experiments (* $P<0.05)$. cells transfected with si-Luciferase or si-MRP1 for indomethacin concentrations up to $100 \mu \mathrm{M}$.

\section{Effect of indomethacin on GSH levels}

To investigate whether the protective effect of MRP1 siRNA against indomethacin-induced apoptosis is not only related to a reduction in MRP1 activity but also to an effect on cellular GSH levels, we measured intracellular GSH concentrations. $\mathrm{GLC}_{4}$ cells have a slightly lower although not significant GSH content of $9.9 \pm 2.2 \mu \mathrm{g}$ mg of total cellular protein compared with $\mathrm{GLC}_{4}-\mathrm{Adr}$ cells with a cellular GSH content of $11.1 \pm 6.1 \mu \mathrm{g} \mathrm{mg}^{-1}(P=0.75)$.

Interfering with the MRP1 function did not affect cellular GSH levels in either cell line. First, downregulation of MRP1 with siMRP1 transfection did not alter intracellular GSH content in $\mathrm{GLC}_{4}$ and $\mathrm{GLC}_{4}$-Adr. Second, when cells were exposed to $50 \mu \mathrm{M}$ of the specific MRP1 inhibitor MK571 for $2 \mathrm{~h}$, GSH levels were not affected and no apoptosis was induced. Higher concentrations of MK571 up to $100 \mu \mathrm{M}$ did induce apoptosis (data not shown). Indomethacin exposure alone, however, lowered GSH levels by $31.5 \pm 19.8 \%$ in $\mathrm{GLC}_{4}$-Adr cells $(P<0.05)$ and by $20.6 \pm 37.7 \%$ in $\mathrm{GLC}_{4}$ cells $(P=0.28)$ (Figure 3$)$.

To confirm the relationship between GSH levels and indomethacin-induced apoptosis, cellular GSH levels in both cell lines were reduced with BSO treatment. As shown in Figure 4, GSH levels were diminished after $\mathrm{BSO}$ treatment in $\mathrm{GLC}_{4}$-Adr cells. This resulted in an increase in apoptosis levels in $\mathrm{GLC}_{4}$ - $\mathrm{Adr}$ cells treated with indomethacin in combination with $\mathrm{BSO}$ compared with $\mathrm{GLC}_{4}{ }^{-}$ Adr cells treated with indomethacin only, for example, from 14.1 to $35.8 \%$ apoptosis at $25 \mu \mathrm{m}$ indomethacin (Figure 5). However, at higher indomethacin concentrations, the relative increase in apoptosis was less pronounced. Indomethacin in combination with BSO did not induce apoptosis in $\mathrm{GLC}_{4}$ at any of these concentrations.

These results indicate that cellular GSH levels are not primary determinants for MRP1-independent indomethacin-induced apoptosis, since GSH depletion did not result in indomethacin-induced apoptosis in $\mathrm{GLC}_{4}$ cells. Furthermore, it suggests that at relatively low indomethacin concentrations GSH levels may be determinants of indomethacin-induced apoptosis in an MRP1-dependent manner.

\section{Indomethacin-induced loss of mitochondrial membrane potential}

Previously, we have demonstrated that indomethacin-induced apoptosis in $\mathrm{GLC}_{4}$-Adr was caused by caspase- 8 as well as caspase9 activation (De Groot et al, 2005). However, the role of mitochondria in indomethacin-induced apoptosis in $\mathrm{GLC}_{4}-\mathrm{Adr}$ was not established. Therefore, we determined whether indomethacin-mediated apoptosis induction coincided with loss of mitochondrial membrane potential in the cells. Flow cytometry revealed that after indomethacin exposure for $24 \mathrm{~h}$ two $\mathrm{GLC}_{4}$-Adr cell populations exist, a MitoTracker red-high and a MitoTracker red-low population (Figure 6). The presence of the MitoTracker red-low population $(40.8 \%$ at $150 \mu \mathrm{M}$ of indomethacin) at $24 \mathrm{~h}$ suggests that loss of mitochondrial membrane potential in $\mathrm{GLC}_{4}{ }^{-}$ Adr occurs in conjunction with apoptosis induction, as at $100 \mu \mathrm{M}$ indomethacin, up to $84.6 \%$ of apoptosis was induced. Indomethacin had no effect on mitochondrial membrane potential in $\mathrm{GLC}_{4}$ (Figure 6).

\section{DISCUSSION}

This is the first study demonstrating that indomethacin can induce apoptosis via an MRP1-dependent mechanism in the MRP1overexpressing SCLC cell line $\mathrm{GLC}_{4}$-Adr. Efficient functional 


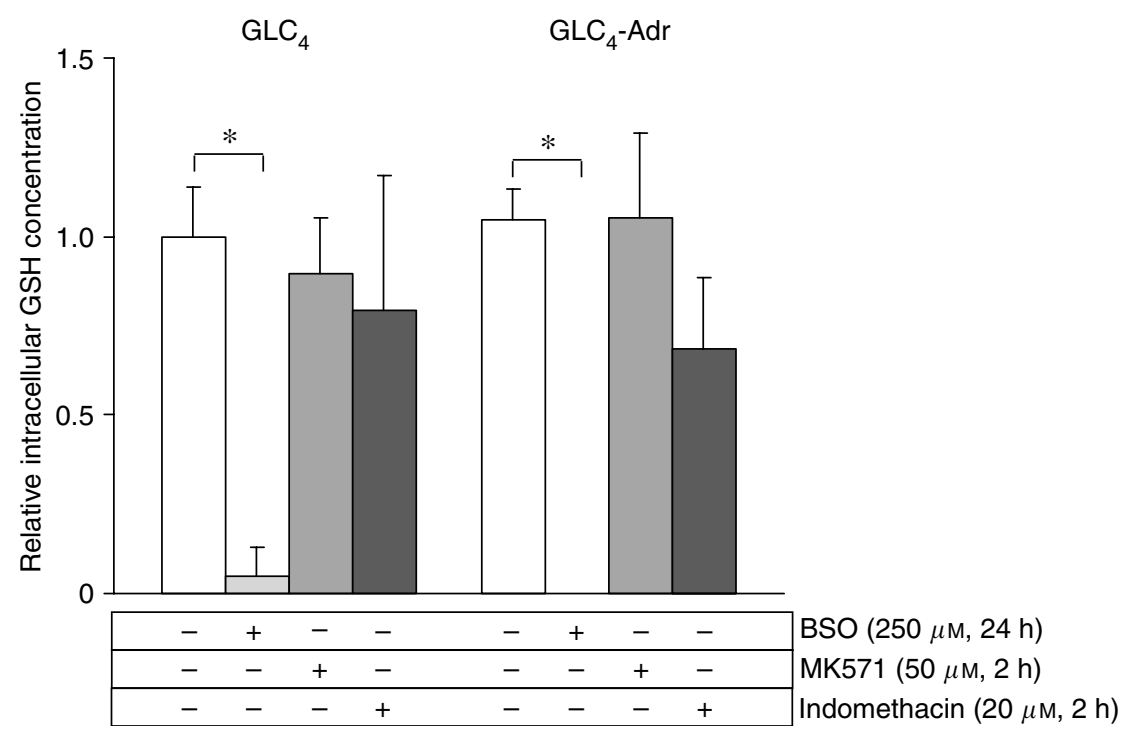

Figure 4 Relative GSH levels in $\mathrm{GLC}_{4}$ and $\mathrm{GLC}_{4}$-Adr cells. Glutathione intracellular concentration was determined after $24 \mathrm{~h}$ BSO, $2 \mathrm{~h}$ MK57। or $2 \mathrm{~h}$ indomethacin exposure. Glutathione levels were calculated as the relative concentration compared with untreated cells. Data represent the mean \pm s.d. of three independent experiments $(* P<0.05)$.
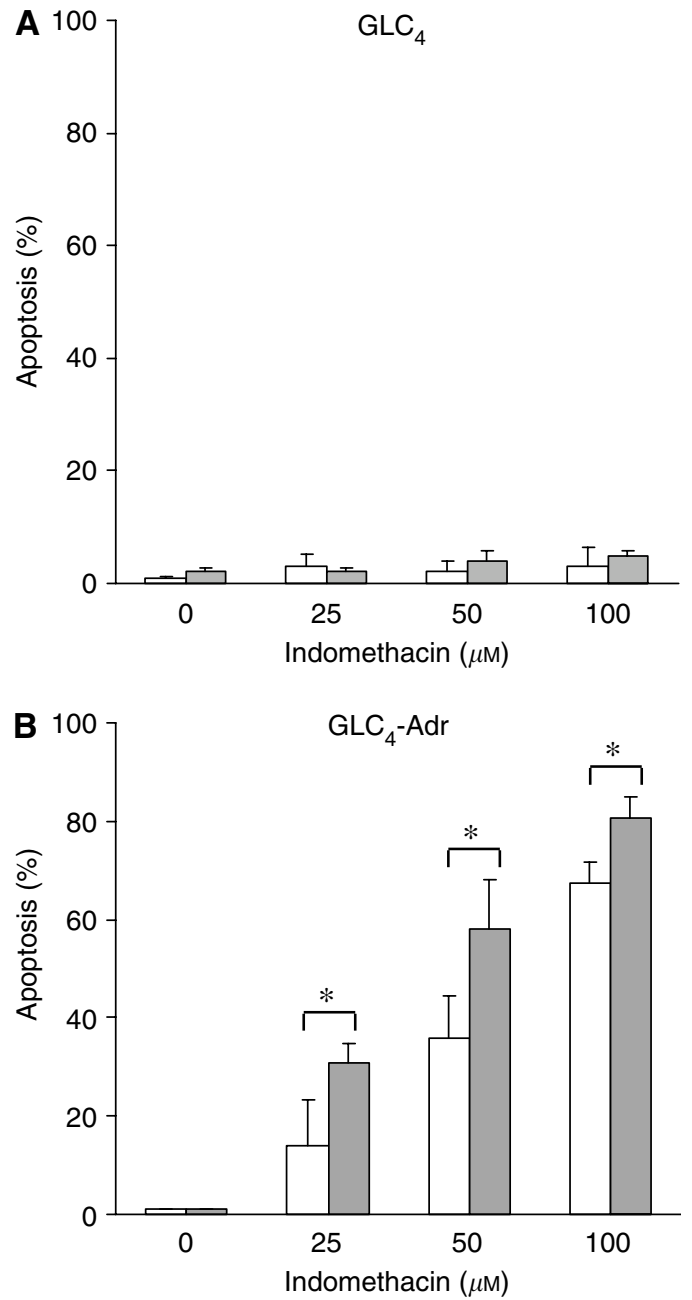

Figure 5 Indomethacin-induced apoptosis in $\mathrm{GLC}_{4}(\mathbf{A})$ and $\mathrm{GLC}_{4}-\mathrm{Adr}$ (B) after $24 \mathrm{~h}$ BSO exposure (grey), or control (white). Cells were exposed to indomethacin for $24 \mathrm{~h}$. No apoptosis was observed in $\mathrm{GLC}_{4}$. Data represent the mean \pm s.d. of three independent experiments $(* P<0.05)$. downregulation of MRP1, as shown using the elevated cellular level of the MRP1 substrate CF, resulted in less apoptosis and concomitantly in enhanced survival of $\mathrm{GLC}_{4}$ - $\mathrm{Adr}$ cells following indomethacin exposure. In contrast, MRP1 downregulation in $\mathrm{GLC}_{4}$ cells had no effect on indomethacin-induced apoptosis or survival. Glutathione levels in $\mathrm{GLC}_{4}-\mathrm{Adr}$ cells were decreased following indomethacin exposure, but these levels were not affected by MRP1 downregulation. In addition, depletion of cellular GSH by BSO made $\mathrm{GLC}_{4}$-Adr cells more sensitive to indomethacin. Since GSH depletion by BSO did not enhance indomethacin-induced apoptosis in $\mathrm{GLC}_{4}$, our results suggest that indomethacin induces apoptosis via an MRP1-dependent mechanism, which may partially be dependent on cellular GSH levels. Another MRP1-dependent mechanism involved is the indomethacininduced activation of the mitochondrial apoptosis pathway, which is reflected in loss of the mitochondrial membrane potential simultaneously with apoptosis induction in $\mathrm{GLC}_{4}$-Adr. These results confirm our previous finding that indomethacin induces apoptosis via activation of caspase- 8 as well as caspase-9 in $\mathrm{GLC}_{4}$ Adr (De Groot et al, 2005).

Indomethacin is a well-known inhibitor of glutathione- $S$ transferase and cyclooxygenase, but it can also affect MRP1 (Draper et al, 1997; Roller et al, 1999). Indomethacin increases chemotherapy sensitivity through inhibition of MRP1 function and stimulation of the GSH efflux in MRP1-overexpressing cell lines, as demonstrated in polarized Madin - Darby canine kidney (MDCKII) cells (Evers et al, 2000). Drug-induced GSH efflux through MRP1 has been described for verapamil in baby hamster kidney-21 cells transfected with human MRP1 (Trompier et al, 2004). The GSH levels in $\mathrm{GLC}_{4}$ and $\mathrm{GLC}_{4}$-Adr are similar, but $\mathrm{GSH}$ turnover is much higher in $\mathrm{GLC}_{4}$-Adr due to its increased MRP1 expression (Kool et al, 1997). In the present study, we demonstrated that GSH levels in $\mathrm{GLC}_{4}$-Adr did not rise after $2 \mathrm{~h}$ exposure to indomethacin. In contrast, GSH levels were even slightly decreased in $\mathrm{GLC}_{4}-\mathrm{Adr}$ but not in $\mathrm{GLC}_{4}$, suggesting that indomethacin-associated MRP1 inhibition does not cause indomethacin-induced apoptosis.

NSAIDs including indomethacin can be metabolized intracellularly generating reactive oxygen species (ROS). The formation of ROS has actually been implicated in indomethacin idiosyncratic toxicity such as bone marrow toxicity or hepatitis (Galati et al, 2002). ROS are inactivated by mitochondrial GSH. In our model, cellular GSH levels were decreased by short exposure to indomethacin. Moreover, the reduction of GSH levels by BSO, a 

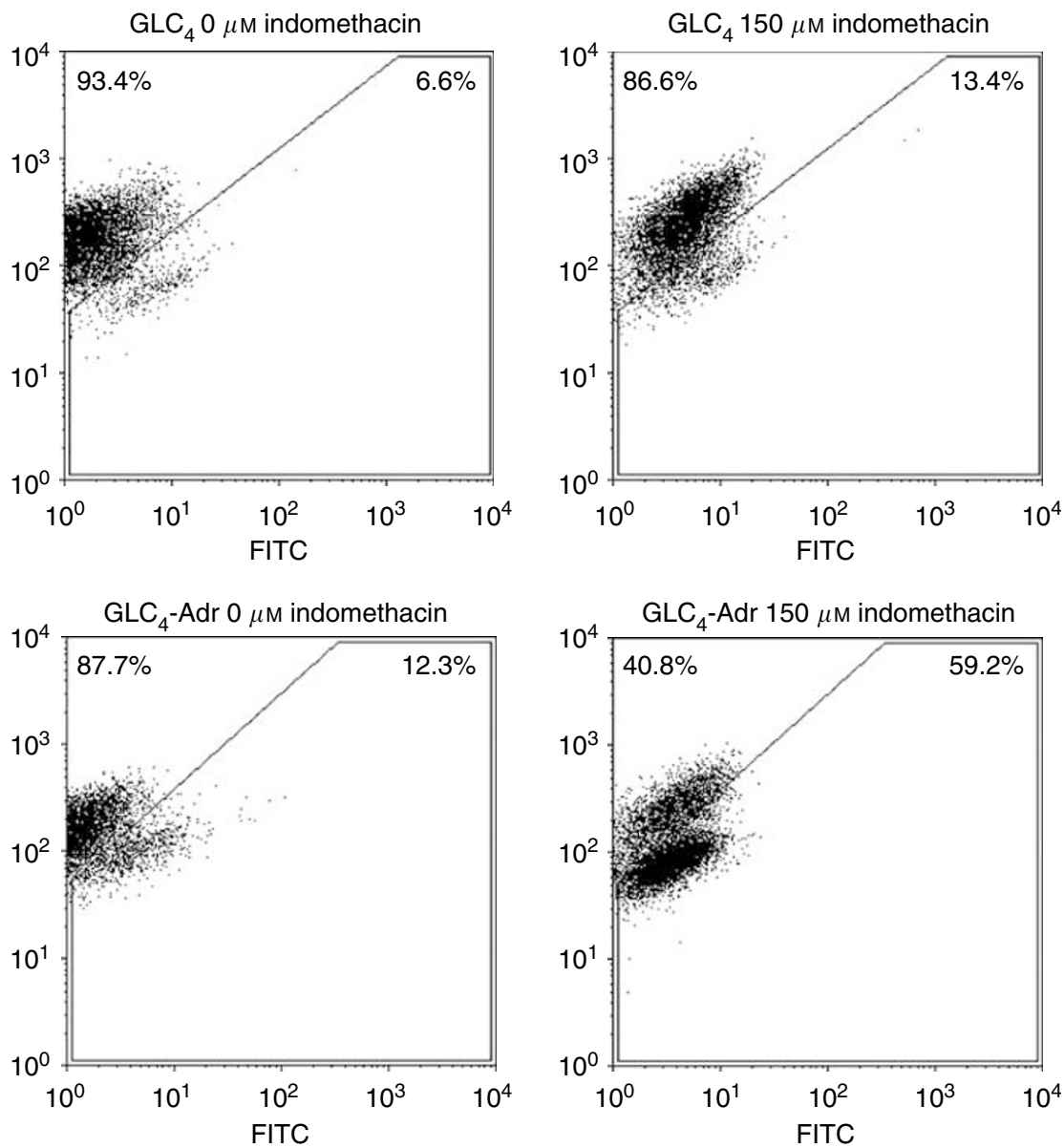

Figure 6 Flow cytometric analysis of intact mitochondria in $\mathrm{GLC}_{4}$ and $\mathrm{GLC}_{4}$-Adr cells after $24 \mathrm{~h}$ exposure to indomethacin and stained with MitoTracker red. Cells not exposed to indomethacin were compared with cells exposed to I50 $\mu \mathrm{M}$ indomethacin. A representative example is shown.

drug that specifically inhibits GSH production, increases indomethacin-mediated apoptosis in $\mathrm{GLC}_{4}-\mathrm{Adr}$ but not in $\mathrm{GLC}_{4}$. A reduction in cellular GSH level can be an important trigger for apoptosis induction as demonstrated in the B-cell lymphoma cell line PW after exposure to BSO (Armstrong et al, 2002). Cellular GSH depletion also resulted in apoptosis in a caspase-8-dependent manner in NCI-H889 SCLC cells, following treatment with the proteasome inhibitor MG132 (Bang et al, 2004). In addition, mitochondria of GSH-depleted cells can become more sensitive to oxidative stress (Henry-Mowatt et al, 2004). Oxidative stress then resulted in the loss of mitochondrial membrane potential and the release of several essential players of the mitochondrial apoptosis pathway, such as cytochrome $c$ and apoptosis-inducing factor into the cytosol as well as the activation of caspases and apoptotic protease-activating factor-1 (Kannan and Jain, 2000; HenryMowatt et al, 2004). Previously, we have shown that inhibition of active caspase- 9 decreased indomethacin-induced apoptosis in $\mathrm{GLC}_{4}$-Adr cells by $44 \%$, suggesting the involvement of the mitochondrial apoptosis pathway (De Groot et al, 2005). In the present study, we demonstrated that indomethacin actually causes loss of mitochondrial membrane potential and subsequently results in the activation of the mitochondrial apoptosis pathway in $\mathrm{GLC}_{4}$-Adr cells. Further research is needed to establish the role of oxidative stress in the loss of the mitochondrial potential. Taken together our results indicate that indomethacin-induced apoptosis in $\mathrm{GLC}_{4}$ - $\mathrm{Adr}$ cells is dependent on MRP1 expression. Indomethacin-induced apoptosis is accompanied by loss of mitochondrial membrane potential. Activation of this pathway may be further enhanced by caspase- 8 activation and Bid cleavage, which we have reported earlier for indomethacin-treated $\mathrm{GLC}_{4}-\mathrm{Adr}$ cells (De Groot et al, 2005).

Downregulation of MRP1 and concomitant loss of MRP1 function slightly decreased indomethacin sensitivity indicating that MRP1 activity facilitates indomethacin-mediated apoptosis. However, one has to take in account that the MRP1 downregulation was not complete, so the effect of MRP1 activity on indomethacin-induced apoptosis is probably underestimated in this model. In addition, GSH depletion by BSO increases indomethacin-mediated apoptosis in $\mathrm{GLC}_{4}$-Adr only. These two findings indicate that the MRP1 function is important in indomethacin-induced apoptosis. The exploitation of a chemotherapy resistance factor such as MRP1 to induce apoptosis is a novel and potentially interesting finding.

In the future, identification of MRP1-overexpressing tumours and exposure of these tumours to combination therapies including indomethacin may provide a novel approach in the treatment of MRP1-overexpressing cancers.

\section{ACKNOWLEDGEMENTS}

We thank M van der Toorn (Department of Allergy) for his help with the GSH assays. This study is supported by grant $99-1880$ of the Dutch Cancer Society, The Netherlands Asthma Foundation (NAF97.35) and the 'Stichting Astma Bestrijding' (SAB). 


\section{REFERENCES}

Allen S, Shea JM, Felmet T, Gadra J, Dehn PF (2000) A kinetic microassay for glutathione in cells plated on 96-well microtiter plates. Methods Cell Sci 22: $305-312$

Armstrong JS, Steinauer KK, Hornung B, Irish JM, Lecane P, Birrell GW, Peehl DM, Knox SJ (2002) Role of glutathione depletion and reactive oxygen species generation in apoptotic signaling in a human B lymphoma cell line. Cell Death Differ 9: 252-263

Ballatori N, Hammond CL, Cunningham JB, Krance SM, Marchan R (2005) Molecular mechanisms of reduced glutathione transport: role of the MRP/CFTR/ABCC and OATP/SLC21A families of membrane proteins. Toxicol Appl Pharmacol 204: 238-255

Bang JH, Han ES, Lim I, Lee CS (2004) Differential response of MG132 cytotoxicity against small cell lung cancer cells to changes in cellular GSH contents. Biochem Pharmacol 68: 659-666

Cole SPC, Sparks KE, Fraser K, Loe DW, Grant CE, Wilson GM, Deeley RG (1994) Pharmacological characterization of multidrug resistant MRP transfected human tumor cells. Cancer Res 54: 5902-5910

De Groot DJ, Timmer T, Spierings DC, Le TK, de Jong S, de Vries EG (2005) Indomethacin-induced activation of the death receptor-mediated apoptosis pathway circumvents acquired doxorubicin resistance in SCLC cells. Br J Cancer 92: 1459-1466

De Jong S, Zijlstra JG, de Vries EG, Mulder NH (1990) Reduced DNA topoisomerase II activity and drug-induced DNA cleavage activity in an adriamycin-resistant human small cell lung carcinoma cell line. Cancer Res 50: 304-309

Draper MP, Martell RL, Levy SB (1997) Indomethacin-mediated reversal of multidrug resistance and drug efflux in human and murine cell lines overexpressing MRP, but not P-glycoprotein. $\mathrm{Br} J$ Cancer 75: $810-815$

Evers R, de Haas M, Sparidans R, Beijnen J, Wielinga PR, Lankelma J, Borst $P$ (2000) Vinblastine and sulfinpyrazone export by the multidrug resistance protein MRP2 is associated with glutathione export. $\mathrm{BrJ}$ Cancer 83: 375 - 383

Galati G, Tafazoli S, Sabzevari O, Chan TS, O’Brien PJ (2002) Idiosyncratic NSAID drug induced oxidative stress. Chem Biol Interact 142: 25-41

Glisson BS (2003) Recurrent small cell lung cancer: update. Semin Oncol 30: $72-78$

Henry-Mowatt J, Dive C, Martinou JC, James D (2004) Role of mitochondrial membrane permeabilization in apoptosis and cancer. Oncogene 23: $2850-2860$

Kannan K, Jain SK (2000) Oxidative stress and apoptosis. Pathophysiology 7: $153-163$

Kool M, de Haas M, Scheffer GL, Scheper RJ, van Eijk MJ, Juijn JA, Baas F, Borst P (1997) Analysis of expression of cMOAT (MRP2), MRP3, MRP4, and MRP5, homologues of the multidrug resistance-associated protein gene (MRP1), in human cancer cell lines. Cancer Res 57: $3537-3547$
Meijer C, Mulder NH, Timmer-Bosscha H, Peters WH, de Vries EG (1991) Combined in vitro modulation of adriamycin resistance. Int J Cancer 49: $582-586$

Müller M, Meijer C, Zaman GJ, Borst P, Scheper RJ, Mulder NH, de Vries EG, Jansen PL (1994) Overexpression of the gene encoding the multidrug resistance-associated protein results in increased ATP-dependent glutathione S-conjugate transport. Proc Natl Acad Sci USA 91: 1303313037

Paul S, Breuninger LM, Tew KD, Shen H, Kruh GD (1996) ATP dependent uptake of natural product cytotoxic drugs by membrane vesicles establishes MRP as a broad specificity transporter. Proc Natl Acad Sci USA 93: 6929-6934

Roller A, Bahr OR, Streffer J, Winter S, Heneka M, Deininger M, Meyermann R, Naumann U, Gulbins E, Weller M (1999) Selective potentiation of drug cytotoxicity by NSAID in human glioma cells: the role of COX-1 and MRP. Biochem Biophys Res Commun 259: 600-605

Ros JE, Roskams TA, Geuken M, Havinga R, Splinter PL, Petersen BE, LaRusso NF, van der Kolk DM, Kuipers F, Faber KN, Müller M, Jansen PL (2003) ATP binding cassette transporter gene expression in rat liver progenitor cells. Gut 52: $1060-1067$

Timmer-Bosscha H, Hospers GA, Meijer C, Mulder NH, Muskiet FA, Martini IA, Uges DR, de Vries EG (1989) Influence of docosahexaenoic acid on cisplatin resistance in a human small cell lung carcinoma cell line. J Natl Cancer Inst 81: 1069-1075

Touhey S, O'Connor R, Plunkett S, Maguire A, Clynes M (2002) Structureactivity relationship of indomethacin analogues for MRP-1, COX-1 and COX-2 inhibition. Identification of novel chemotherapeutic drug resistance modulators. Eur J Cancer 38: $1661-1670$

Trompier D, Chang XB, Barattin R, du Moulinet D'Hardemare A, Di Pietro A, Baubichon-Cortay $\mathrm{H}$ (2004) Verapamil and its derivative trigger apoptosis through glutathione extrusion by multidrug resistance protein MRP1. Cancer Res 64: 4950-4956

Van der Kolk DM, de Vries EG, Koning JA, van den Berg E, Muller M, Vellenga E (1998) Activity and expression of the multidrug resistance proteins MRP1 and MRP2 in acute myeloid leukemia cells, tumor cell lines, and normal hematopoietic CD34+ peripheral blood cells. Clin Cancer Res 4: $1727-1736$

Wang W, Ballatori N (1998) Endogenous glutathione conjugates: occurrence and biological functions. Pharmacol Rev 50: 335-356

Zaman GJ, Flens MJ, van Leusden MR, de Haas M, Mülder HS, Lankelma J, Pinedo HM, Scheper RJ, Baas F, Broxterman HJ, Borst P (1994) The multidrug resistance-associated protein MRP is a plasma membrane efflux pump. Proc Natl Acad Sci USA 91: 8822-8826

Zijlstra JG, de Vries EG, Mulder NH (1987) Multifactorial drug resistance in an adriamycin-resistant human small cell lung carcinoma cell line. Cancer Res 47: 1780-1784 